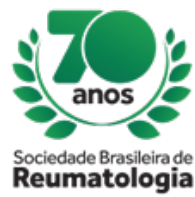

\title{
SEVERE EXTRAARTICULAR MANIFESTATIONS IN RHEUMATOID ARTHRITIS IN THE ABSENCE OF RHEUMATOID FATOR (RF) AND ANTI-CCP: A CASE REPORT
}

Bruna Giusto Bunjes (Hospital das Clínicas da Faculdade de Medicina da USP, SAO PAULO, SP, Brasil), Gisela Rios Machado (Hospital das Clínicas da Faculdade de Medicina da USP, SAO PAULO, SP, Brasil), Glaucia Ferreira Abrahão (Hospital das Clínicas da Faculdade de Medicina da USP, SAO PAULO, SP, Brasil), Felipe Freire Silva (Hospital das Clínicas da Faculdade de Medicina da USP, SAO PAULO, SP, Brasil), Eduardo Ferreira Borba (Hospital das Clínicas da Faculdade de Medicina da USP, SAO PAULO, SP, Brasil), Lissiane Karine Noronha Guedes (Hospital das Clínicas da Faculdade de Medicina da USP, SAO PAULO, SP, Brasil), Luciana Parente Costa Seguro (Hospital das Clínicas da Faculdade de Medicina da USP, SAO PAULO, SP, Brasil), Rosa Maria Rodrigues Pereira (Hospital das Clínicas da Faculdade de Medicina da USP, Sao Paulo, SP, Brasil)

\section{BACKGROUND}

Rheumatoid arthritis (RA) is an autoimmune disease resulting in joint destruction associated with extraarticular and systemic manifestations. The development of rheumatoid vasculitis are more frequently in seropositive patients. We present a patient with confirmed RA without the presence of Rheumatoid Factor (RF), with severe neurologic manifestations and skin involvement.

\section{CASE REPORT}

A patient with chronic arthralgia develops progression of arthritis with loss of function; presented with an ulcerous lesion in the right lower limb, with external biopsy compatible with Pyoderma Gangrenosum. Physical examination of the joints reveals swelling, pain and stiffness. Later with extreme difficulty for ambulation, with symmetric motor loss of lower limbs and altered sensitivity, keeping an exuberant joint activity and nodules in the extensor surface of the forearm.

Infections or malignancy were excluded. Immunological profile showed negative RF and AntiCCP. There was an expressive elevation of inflammatory tests, which reduced considerably after the introduction of corticosteroid. Neurologic tests showed lesion of upper and lower motor-neurons. Electroneuromyography revealed increased latency of responses in all four limbs. A magnetic resonance image of wrists described clear signs of erosion of the styloid process of the ulna, synovitis of the distal radioulnar, radiocarpal and carpometacarpal joints, highly suggestive of active inflammatory arthropathy.

Considering the possible diagnosis of seronegative RA with vasculitic neuropathy, the treatment was methylprednisolone and cyclophosphamide. Patient was discharged with ambulatory follow-up, after three months presented with significant improvement.

\section{CONCLUSION}

Severe extraarticular RA often has high levels of RF at presentation, ranging from 75 to $80 \%$. The skin is frequently involved. Neurologic abnormalities could be seen, such as sensory or sensor motor axonal neuropathy, as well as rare manifestations including ischemic neuropathy due to rheumatoid vasculitis (RV).

Vasculitic neuropathy is a frequent component of RV, although RV itself is unusual. The neuropathy in these patients results from infarction of peripheral nerves affecting the vasa nervorum. Approximately $40 \%$ of patients with RV have a sensory neuropathy, and up to $20 \%$ develop manifestations of a mixed motor and sensory neuropathy.

Extraarticular involvement in RA is a marker of disease severity and increased of mortality. Successful management of systemic manifestations of RA is predicated upon control of the underlying joint disease. 
This case reinforces the importance of the clinical and image diagnosis in RA with severe extra articular manifestations, despite seronegative disease. 